
\title{
28 Research Square \\ Relationship between Internet use and leaving home during the first wave of the COVID-19 outbreak in Japan
}

Naoto Yabe ( $\nabla$ yabebeya@tmu.ac.jp )

Tokyo Metropolitan University https://orcid.org/0000-0002-7586-4255

Tomoya Hanibuchi

Tohoku University

Hiroki M. Adachi

Tohoku University

Shohei Nagata

Tohoku University

Tomoki Nakaya

Tohoku University

\section{Research Article}

Keywords: COVID-19, Internet, outings, substitution relationship, the Declaration of a State of Emergency, Japan

Posted Date: November 17th, 2020

DOI: https://doi.org/10.21203/rs.3.rs-108313/v1

License: (1) This work is licensed under a Creative Commons Attribution 4.0 International License.

Read Full License 


\section{Abstract}

Following the first wave of the COVID-19 outbreak, the Japanese government announced the Declaration of a State of Emergency in April 2020, which aimed to decrease contact between people and requested that residents refrain from leaving home. Even in the absence of penalties, outings decreased under the declaration. We are interested in how outings declined and studied the substitution relationship between Internet use and outings. A web-based survey was conducted to collect data on Internet use and outings in a retrospective manner. The period covered by our data is from mid-February to mid-May 2020. Multilevel analysis and correspondence analysis were performed to examine the relationship between Internet use and outings. The results clearly show that Internet use replaced outings. In particular, Internet use for socializing, exercise, and leisure/entertainment had a significant substitution relationship with outings. In contrast, there was a weak substitution relationship between Internet use for daily shopping and outings. Although telework tends to be an accepted focus of Internet use under the COVID-19 outbreak, it should not be overlooked that other uses of the Internet, such as for leisure/entertainment, also supported the decline in outings.

\section{Introduction}

In Japan, the number of confirmed COVID-19 cases has been clearly increasing since late February 2020, and the peak of the first wave occurred around mid-April (Figure 1). To prevent the spread of COVID-19, the Japanese government and local governments started to ask people to work remotely and refrain from holding large events in February. On February 27, the Japanese government also requested that elementary, middle, and high schools all over Japan close from March 2 until spring break. Finally, a Declaration of a State of Emergency for the metropolitan areas was announced by the Japanese government on April 7. The declaration was extended to all of Japan on April 16. It was lifted on May 14 for the nonmetropolitan areas and on May 25 for the remaining metropolitan areas.

The aim of the declaration was to limit the spread of infection in order to reduce the burden on medical facilities. To this end, people were asked to refrain from leaving their homes, with the aim of reducing contact between people by $80 \%$. To achieve with this aim, the following were requested in the declaration: people should work at home, except for those with jobs necessary to maintain the functioning of society; when people have to go out for necessities, the three Cs ("closed spaces with poor ventilation", "crowded places with many people", and "close contact with other people") should be avoided, and all must wear a mask. In addition, the declaration gave prefectural governors legal grounds to request the closure of facilities that host many people and shortened hours of operation for restaurant. In fact, most of the prefectures made these requests.

It is believed that reducing outings is effective in preventing the spread of infection by reducing contact between people, and some countries imposed severe restrictions on outings, including penalties ${ }^{1-4}$. The Declaration of a State of Emergency in Japan was similar to other countries' policies in that it aimed to 
reduce contact between people. However, the declaration in Japan was unique in that it was formulated as a request, not a mandate. Despite this, outings in Japan decreased ${ }^{5,6}$.

How was this reduction in outings achieved under a request-based policy with no penalties? Although there have been studies on the impact of lockdown policies on COVID-19 cases or epidemiological dynamics $13,4,7,8$, it is not clear how the reduction in outings was achieved in countries with relatively modest restrictions on outings. More precisely, it is self-evident that there has been a decrease in outings in countries with severe restrictions, but it is not clear what supports this decrease in outings in countries, such as Japan, with a request-based policy. However, few studies have tackled this problem, though one study on the association between stigma and outings in Japan has been published ${ }^{9}$. That study showed that outings decreased during the period of the Declaration of a State of Emergency, but it is not clear whether this was due simply to stigma. Stigma is unlikely to be the only factor that reduces outings. Understanding the factors associated with the reduction in outings will help us to plan measures that do not involve severe restrictions for subsequent waves of the disease.

In this study, we focus on Internet use as a factor related to the decrease in outings. Internet use as a substitute for outings has received much attention, and it has been reported that Internet use has actually increased in various ways, including because of telework and online shopping ${ }^{10-13}$. However, there is little empirical evidence of the relationship between Internet use and outings under the COVID-19 outbreak, what kind of Internet use especially replaces going out, and to what extent.

Various studies had already been conducted on the relationship between Internet use and outings before the COVID-19 outbreak. Existing research suggests that there are two main relationships between Internet use and outings: substitution and complementary ${ }^{14}$. The substitution relationship is one in which outings decrease as Internet use increases. The complementary relationship is one in which outings increase as Internet use increases.

Among the purposes of Internet use, telework and online shopping have received much attention, and other purposes, such as online gaming or accessing online movies, have not been studied as much. Based on existing research, telework is clearly related to reduced outings, whereas online shopping is more complementary than substitutional ${ }^{15}$. For Internet use other than telework and online shopping, the relationship with outings is not clear. It is also not known which purpose of Internet use reduces outings to a greater degree. Each purpose of Internet use was examined independently in previous studies. Under the COVID-19 outbreak, people use the Internet for various purposes. Thus, it is important to examine the relationship between Internet use and outings while considering multiple purposes of Internet use.

The present study, therefore, aims to clarify the relationship between Internet use and outings while taking into account various purposes of Internet use at the same time. The period of investigation is from midFebruary to mid-May 2020, which covers the duration of the Declaration of a State of Emergency. We expect a substitution relationship between Internet use and outings for that period. In the following, data 
are collected through a web-based survey and analyzed to determine the relationship between Internet use and outings.

\section{Methods}

\section{Questionnaire survey}

A web-based questionnaire survey was conducted to collect data about Internet use and outings. The study participants were recruited from among the registrants of the survey company Cross Marketing Inc., which can access approximately 4.65 million registered monitors residing in Japan. In the recruitment process for this study, quota sampling was conducted so that the sample distributions by age group (20s, $30 \mathrm{~s}, 40 \mathrm{~s}, 50 \mathrm{~s}$ and $60 \mathrm{~s}$ ), gender (male and female) and place of residence (metropolitan area and nonmetropolitan area) were representative of the Japanese population. The quota was calculated based on the 2015 Japanese population census. The web survey started on May 19 and ended on May 23, 2020. The target number of total participants was 1,200 , and participants were accepted until that number was reached. During the screening process for the web survey, participants were limited to iPhone users because step count data from the iPhone were collected in the survey.

Unfortunately, the quota for participants in their 60 s living in nonmetropolitan areas was not reached. Considering sampling bias, the following analyses exclude the sample in the 60 s age group. Thus, the total sample size used in the following analyses is 928 .

This questionnaire survey was approved by the Research Ethics Committee of the graduate school of engineering, Tohoku University (20A-3). Informed consent was obtained from all the respondents.

\section{Measuring Internet use and outings}

This section describes how Internet use and outings were measured in the questionnaire survey. In the survey, we asked the following question about Internet use: "For what purposes has your use of the Internet increased after the COVID-19 outbreak?" The answers to that question can be selected from the following options: daily shopping, non-daily shopping, mail/messages, socializing (for example, online drinking parties), exercise, leisure/entertainment, and work/study. In addition, the following question was also asked about Internet access: "When you use the Internet at home, do any of the following apply to you?" The answers to that question can be selected from the following options: don't have a broadband connection, traffic volume is limited, don't know how to shop online, workplace doesn't support telework, and don't have a personal computer.

Two questions were asked about outings. In the first question, we asked for the time spent outside from mid-February to mid-May with a time interval of 10 days. That is, respondents reported their time spent outside from mid-February, late February, early March, and so on. Time spent outside was reported in integers relative to 10 , which reflects the usual time spent outside before the COVID-19 outbreak. That is, 
if a respondent thinks that the time he or she spent outside during a certain period was half that spent outside before the outbreak, the respondent assigns a value of 5 to that time period. This value of time spent outside is subjective, but characteristic events in each time period were described in the survey to reduce recall bias. The second question about outings was "Where do you refrain from going to?" The answers to that question can be selected from the following options: supermarket, convenience store, park, shopping mall, restaurant, and workplace/school.

\section{Multilevel analysis}

The relationship between Internet use and outings was analyzed from two perspectives. The first explore what kind of Internet use especially replaces going out, and to what extent. The second explores for which destinations outings have decreased with increased use of the Internet. A multilevel linear regression model for longitudinal data ${ }^{16}$ was applied to analyze the relationship between Internet use and time spent outside. That is, it addresses the first perspective described above.

The multilevel linear regression model is divided into level 1 and level 2. Level 1 describes the variation in time spent outside within an individual. The equation for level 1 is as follows:

$$
Y_{i j}=\beta_{0 j}+\beta_{1 i} \text { Time }_{i j}+\beta_{2} x_{1 i}+\beta_{3} x_{2 i}+r_{i j}
$$

where $Y_{\mathrm{ij}}$ is respondent $j$ s time spent outside in time period $i$, and $i$ takes a value from 1 to 10 (from midFebruary to mid-May). $\beta_{0 j}$ is the intercept for respondent $j, \beta_{1 j}$ is the slope for respondent $j$, Time $e_{i j}$ takes the value of $i$, and $r_{\mathrm{ij}}$ is respondent $j$ 's variance in time period $i$ assuming a normal distribution independent of each time period with a mean of $0 . x_{1 i}$ and $x_{2 i}$ are variables that control the effect of school closure and the Declaration of a State of Emergency, respectively. The variable $x_{1 i}$ is a dummy variable that indicates the impact of the request for school closure nationwide that was implemented from March 2, and that takes a value of 0 until at the end of February (from $i=1$ to 2 ) and 1 thereafter (from $i=3$ to 10). The $x_{2 i}$ variable is a dummy variable that indicates the impact of the Declaration of a State of Emergency on April 7 and 16. It takes a value of 0 until late March (from $i=1$ to 5 ) and 1 thereafter for seven prefectures that are largely metropolitan areas, including Tokyo. For the other 40 prefectures, it takes 0 until early April (from $i=1$ to 6 ) and 1 thereafter. Regarding this $x_{2 i}$ variable, the Declaration of a State of Emergency was lifted for 39 prefectures that are largely nonmetropolitan areas on May 14. Thus, $x_{2 i}$ takes 0 in mid-May $(i=10)$ for the 39 prefectures. $\beta_{2}$ and $\beta_{3}$ are parameters for each variable.

Level 2 describes variations in intercept and slope from level 1 between individuals:

$$
\begin{gathered}
\beta_{0 j}=\gamma_{00}+u_{0 j} \\
\beta_{1 j}=\gamma_{10}+\sum_{n=1}^{k} \gamma_{1 n} z_{n j}+u_{1 j}
\end{gathered}
$$


where $\gamma_{00}$ and $\gamma_{10}$ are intercepts that capture the average of the sample, and $u_{0 j}$ and $u_{1 j}$ are betweenrespondent variance assuming a normal distribution with a mean of 0 . Since the present study is interested in the slope from level 1 , which represents the changes in outings over time well, explanatory variables $z_{\mathrm{nj}}$ are inserted only into the equation for $\beta_{1 \mathrm{j}}$. $k$ is the number of explanatory variables.

The explanatory variables $z_{\mathrm{nj}}$ can be divided into four categories: 1 ) the purposes of Internet use that increased after the COVID-19 outbreak, 2) Internet access, 3)personal attributes (age and gender), and 4) commercial district.

The details of the variables are as follows. The purposes of Internet use consist of seven variables: daily shopping, non-daily shopping, mail/messages, socializing, exercising, leisure/entertainment, and work/study. Each variable takes 1 if the purpose of Internet use increased after the outbreak, and 0 otherwise. If we find a negative coefficient for ${ }_{1 n}$ for an Internet use variable, we assume that there is a substitution relationship.

Internet access consists of five variables: don't have a broadband connection, traffic volume limits, don't know how to shop online, workplace doesn't support telework, and don't have a personal computer. Those variables take 1 if the Internet access option applies and 0 otherwise.

For personal attributes, respondents are divided into age groups (20s, 30s, 40s and $50 \mathrm{~s})$; there are three dummy variables, and the 20s age group is the referent. Gender is also a dummy variable that takes 1 for male and 0 otherwise. Commercial district is a variable that takes 1 if the respondent's residence is within a commercial district ${ }^{17}$ and 0 otherwise.

Of the 928 samples, 906 were included in this multilevel analysis. The responses with a maximum time spent outside larger than 20 (7 respondents) were excluded as outliers; 15 respondents whose zip codes did not match their actual addresses were also excluded. The ImerTest package ${ }^{18}$ in the R version 3.6.1 environment was used for the multilevel analysis.

\section{Correspondence analysis}

A correspondence analysis was employed to address the second perspective above that explores for which destinations outings have decreased with increased use of the Internet. The multilevel analysis reveals which kind of Internet use especially substitutes for time spent outside. Based on the multilevel analysis, however, we do not know which destinations have seen decreased visits or which types of Internet use are associated with this decline. Therefore, the correspondence analysis is appropriate for further investigation of the relationship between Internet use and outings.

The correspondence analysis was conducted via a cross-tabulation table, with the less visited destinations as the head of the table and the increased Internet use purposes as the stubs. 
All 928 sample were used in the correspondence analysis. The statistical software BellCurve for Excel version 3.20 was used for the correspondence analysis.

\section{Results}

\section{Descriptive statistics}

The descriptive statistics of the survey sample are summarized in Table 1. On the right side of the table, the sample that is representative of the Japanese population in terms of age, gender and place of residence is shown. This total of 928 samples is used in the correspondence analysis. On the left side of the table, the statistics for the 906 samples used for the multilevel analysis are shown. Regarding the distribution by age, gender and place of residence, there seems to be little difference between this sample and the representational sample on the right side of the table.

Notably, Internet use for leisure/entertainment purposes increased the most. Shopping malls and restaurants are the destinations that the most respondents refrained from visiting, at over $70 \%$ of respondents. Time spent outside decreased almost linearly from mid-February to early May; the increase in mid-May might be due to the lifting of the Declaration of a State of Emergency in 40 prefectures.

\section{Multilevel analysis}

We first present the results for Model 1 (Table 2). Model 1 is the so-called unconditional means model that includes only the level 2 intercept $Y_{00}$. The purpose of Model 1 is to compare the magnitude of the within-individual and between-individuals variance. The within-individual variance is 6.871 , the betweenindividuals variance is 4.012 , and the between-individuals variance accounts for $37 \%$ of the total variance. This indicates that there are good reasons to fit the multilevel model to the data.

Next, all explanatory variables were inputted and reanalyzed, excluding those that were not statistically significant at the $5 \%$ level. The results of the analysis with only the statistically significant variables are shown in Model 2. For all Internet use, negative coefficients are estimated, indicating that time spent outside decreases as the use of the Internet increases. In particular, the relation is strong for the socializing, exercise, and leisure/entertainment purposes. For example, the coefficient for socializing is -0.151 , indicating a decrease of 1.51 points in time spent outside over the study period (from midFebruary to mid-May). The coefficient for the use of the Internet for daily shopping is not as large. A positive coefficient is estimated for the variable representing the workplace not supporting telework. Thus, if a workplace does not support telework, the decline in the time spent outside is slower over time.

Regarding the variables, positive coefficients are estimated for male and for living in a commercial district, both of which have a moderate relation with the decrease in time spent outside. Negative coefficients are estimated for school closure and the Declaration of a State of Emergency, indicating that these measures had the effect of reducing the time spent outside by approximately one point. 
To better understand the results of the multilevel analysis, a graph that shows the estimated changes in time spent outside based on Model 2 is provided (Figure 2). The baseline (dashed line) shows estimates calculated using only the slope $\gamma_{00}$ and intercept $\gamma_{10}$ of Model 2 , without the explanatory variables. In this case, the time spent outside decreased to approximately five points in mid-May. The thin line shows estimates calculated by adding the coefficient of Internet use for leisure/entertainment to the baseline. This coefficient is chosen because most of the respondents used the Internet for leisure/entertainment according to Table 1. The slope of the thin line is steeper than that of the dashed line because the effects of Internet use for leisure/entertainment are included. Finally, the bold line adds the effects of school closure (early March) and the Declaration of a State of Emergency (early April). For the bold line, the time spent outside reached 2.5 points in mid-May. This bold line reflects the situation in metropolitan areas, where the Declaration of a State of Emergency was not lifted until May 25.

\section{Correspondence analysis}

In the correspondence analysis, we plot the results up to the second dimension (Figure 3), as the cumulative contribution up to the second dimension reached $96.5 \%$ of the total variance. Figure 3 a shows the Internet use purposes, where work/study is on the positive side of the first dimension, and leisure/entertainment is on the negative side. Therefore, the first dimension is interpreted as the work to private dimension. The second dimension has daily shopping on the positive side and non-daily shopping on the negative side. Therefore, the second dimension is interpreted as the daily to non-daily dimension.

Comparing Figure $3 \mathbf{a}$ and $\mathbf{b}$ reveals relationships between Internet use and outings. The points in similar positions on the two graphs are in correspondence. For example, the point for using the Internet for work/study and the point for refraining from going to work/school are plotted in similar positions on the two graphs. Therefore, it can be concluded that they are related.

There are both expected and unexpected results. The predicted outcomes included the following: an increase in the use of the Internet for work corresponds to refraining from going to work; an increase in the use of the Internet for daily shopping corresponds to refraining from going to the supermarket; and an increase in the use of the Internet for non-daily shopping corresponds to refraining from going to the shopping mall. In addition, the unanticipated results are as follows: an increase in the use of the Internet for daily shopping corresponds to refraining from going to the park, and an increase in the use of the Internet for leisure/entertainment or exercise corresponds to refraining from going to restaurants and shopping malls.

\section{Discussion}

The multilevel analysis revealed statistically significant relations: the use of the Internet for purposes such as socializing, exercise, and leisure/entertainment substituted for time spent outside, which was not known in previous studies. All of these Internet use purposes share a feature in common: they are time 
consuming. Socializing, such as joining an online drinking party, usually takes several hours, and a movie, a typical example of leisure/entertainment, takes approximately two hours. Online games also take a long time. In addition, some people are likely to spend more time exercising when viewing online videos, such as yoga and gymnastics videos, in their homes. Therefore, the relation between such Internet use and time spent outside may have a greater effect than online shopping.

The results of the multilevel analysis show that Internet use for daily shopping has a weaker substitution relationship with outings than other types of Internet use. Research from Germany reported that the surge in demand for online shopping has not been satisfied because of supply shortages ${ }^{11}$. As evidenced by the fact that living within a commercial district tended to increase going out in our multilevel analysis, online shopping alone may not have been able to meet the demand and thus did not strongly suppress going out.

Previous studies in the period before the COVID-19 outbreak have been clear about the substitution relationship between telework and going out ${ }^{15}$, and this association held in this study. However, in this study, the increase in Internet use for work is not simply associated with a decrease in time spent outside. This is because the use of the Internet for work was not a significant variable. Instead, the variable indicating that the workplace does not support telework was significantly related to time spent outside. This suggests that there were cases where work could be done via the Internet, but there were still cases where employees had to go into work for some reason. In Japan, there is a practice of putting a personal seal (Hanko) on documents when approving them, and people sometimes have to visit the office just for this purpose. The results seem to indicate the importance of whether the workplace supports telework, which may entail changes in this practice.

Correspondence analysis revealed that various purposes of Internet use correspond to refraining from outings. An important result is that Internet use for exercising and leisure/entertainment has a relation to refraining from outings to restaurants and shopping malls. It is possible that people who refrain from going out for recreational aims, such as shopping and eating out, are using the Internet for exercise and leisure/entertainment purposes. From Table 1, the number of respondents who refrain from going to restaurants and shopping malls is larger than that for other facilities. In addition, the number of respondents who increased their Internet use for leisure/entertainment purposes is the largest. When combined with the fact that these variables are significant in the multilevel analysis, the decline in outings during the survey period may first be attributed to the substitution of outings to restaurants and shopping malls with Internet use for leisure/entertainment purposes.

According to the results of the correspondence analysis, Internet use for daily shopping corresponds not only to refraining from outings to supermarkets but also to parks. In the Netherland, where relatively moderate restrictions on outings were imposed, outings for grocery shopping and touring/walking increased overall during the COVID-19 outbreak ${ }^{19}$. Google COVID-19 Community Mobility Reports also demonstrate that outings to the grocery/pharmacy and parks show similar trends in Japan, with relatively slower decreases compared to the decreases seen for retail/recreation or workplaces ${ }^{6}$. Since 
supermarkets and parks are often located in residents' neighborhoods, it is likely that a certain number of people will go to both destinations. According to the results of the correspondence analysis, it is possible that the group that visited both the supermarket and the park refrained from going out and used the Internet for daily shopping.

In conclusion, this study confirms that Internet use substituted for outings during the first wave of COVID19 in Japan. In particular, Internet use for socializing, exercise, and leisure/entertainment was associated with decreasing time spent outside. These Internet uses contributed to reducing going out even in the absence of severe restrictions on outings. Although telework tends to be an accepted focus of Internet use, it should not be overlooked that other purposes, such as leisure/entertainment and socializing, also supported the decline in outings. Obviously, it is necessary to address the digital divide while promoting the use of the Internet.

This study has several limitations. First, in the multilevel analysis, the explanatory variable is Internet use, and the outcome is time spent outside. However, it is also possible to assume a relationship in which Internet use increases because people do not go out. In this study, it is not possible to distinguish whether Internet use is a cause or effect. If we could determine when the use of the Internet increased during the study period, this problem might be solved using multilevel analysis. However, regardless of which is the cause and which is the effect, the fact remains that Internet use and outings are in a substitution relationship.

Regarding the second limitation, our sample was not collected via random sampling of the whole Japanese population. Although we used a quota sampling method, well-known biases for online surveys, such as the bias for high-income earners, might be present. The exclusion of the sample in the 60 s age group from our analyses is another reason that makes us cautious regarding the generalization of our results. Furthermore, socioeconomic attributes of the respondents, such as income and education, were not used in this study. Although including these variables did not substantially change the results of the current study, further studies should consider the socioeconomic digital divide in exploring the substitution relationship between Internet use and outings.

Another limitation of this study is that time spent outside was measured by relying on the respondent's subjective memory. Step count information can be used to mitigate this issue. According to our analysis, step count data have a significant relation with time spent outside (see Supplementary Fig. S1 online). Therefore, we believe that the self-reported records used in this analysis are fairly reliable. Nevertheless, when collecting longitudinal data using retrospective methods, it is necessary to carefully consider the method to ensure the reliability of the data.

In addition, Internet use was not the only factor that supported the decline in outings. There may have been other factors related to the decline in outings, such as peer pressure, stigma, fear of infection, store closure, and socioeconomic attributes. This study is a rather simple, preliminary consideration, and future research is needed to ascertain more complex relationships between the related variables. 


\section{References}

1 Koh, W. C., Naing, L. \& Wong, J. Estimating the impact of physical distancing measures in containing COVID-19: an empirical analysis. International Journal of Infectious Diseases, doi:https://doi.org/10.1016/j.ijid.2020.08.026 (2020).

2 Hale, T. et al. Variation in government responses to COVID-19 Version 6.0. Blavatnik School of Government Working Paper 2020/032 (2020).

3 Alfano, V. \& Ercolano, S. The efficacy of lockdown against COVID-19: A cross-country panel analysis. Appl Health Econ Health Policy 18, 509-517, doi:10.1007/s40258-020-00596-3 (2020).

4 Islam, N. et al. Physical distancing interventions and incidence of coronavirus disease 2019: natural experiment in 149 countries. BMJ 370, m2743, doi:10.1136/bmj.m2743 (2020).

5 Yabe, T. et al. Non-compulsory measures sufficiently reduced human mobility in Japan during the COVID-19 epidemic. arXiv: Physics and Society (2020).

6 Google. COVID-19 Community Mobility Reports. (2020).

<https://www.google.com/covid19/mobility/>.

7 Dehning, J. et al. Inferring change points in the spread of COVID-19 reveals the effectiveness of interventions. Science 369, eabb9789, doi:10.1126/science.abb9789 (2020).

8 Gatto, M. et al. Spread and dynamics of the COVID-19 epidemic in Italy: Effects of emergency containment measures. Proceedings of the National Academy of Sciences 117, 10484-10491, doi:10.1073/pnas.2004978117 (2020).

9 Katafuchi, Y., Kurita, K. \& Managi, S. COVID-19 with stigma: Theory and evidence from mobility data. Munich Personal RePEC Archive, 1-30 (2020).

10 Abigail Adams-Prassl, T. B., Golin, M, Rauh, C. Inequality in the impact of the coronavirus shock: Evidence from real time surveys IZA Discussion Papers, 1-49 (2020).

11 Dannenberg, P., Fuchs, M., Riedler, T. \& Wiedemann, C. Digital transition by COVID-19 pandemic? The German food online retail. Tijdschrift voor economische en sociale geografie 111, 543-560, doi:10.1111/tesg.12453 (2020).

$12 \mathrm{Li}$, J., Hallsworth, A. G. \& Coca-Stefaniak, J. A. Changing grocery shopping behaviours among Chinese consumers at the outset of the COVID-19 outbreak. Tijdschrift voor economische en sociale geografie 111, 574-583, doi:10.1111/tesg.12420 (2020).

13 Beck, M. J. \& Hensher, D. A. Insights into the impact of COVID-19 on household travel and activities in Australia - The early days under restrictions. Transport Policy 96, 76-93, 
doi:https://doi.org/10.1016/j.tranpol.2020.07.001 (2020).

14 Senbil, M. \& Ryuichi, K. in Tenth International Conference on Travel Behaviour Research (Lucerne, 2003).

15 Andreev, P., Salomon, I. \& Pliskin, N. Review: State of teleactivities. Transportation Research Part C: Emerging Technologies 18, 3-20, doi:https://doi.org/10.1016/j.trc.2009.04.017 (2010).

16 Singer, J. D. \& Willett, J. B. Applied Longitudinal Data Analysis: Modeling Change and Event Occurrence. (Oxford University Press, 2003). Translated by Sugawara, M. Jyudan data no bunseki. (Asakura Publishing, 2012) in Japanese.

17 Akiyama, Y., Sengoku, H. \& Shibasaki, R. Development of commercial accumulation statistics throughout Japan and utilization environment of them. Theory and Applications of GIS 21, 97-106, doi:10.5638/thagis.21.97 (2013).

18 Kuznetsova, A., Brockhoff, P. B. \& Christensen, R. H. B. ImerTest Package: Tests in Linear Mixed Effects Models. Journal of Statistical Software; Vol 1, Issue 13 (2017) (2017).

19 de Haas, M., Faber, R. \& Hamersma, M. How COVID-19 and the Dutch 'intelligent lockdown' change activities, work and travel behaviour: Evidence from longitudinal data in the Netherlands. Transportation Research Interdisciplinary Perspectives 6, 100150, doi:https://doi.org/10.1016/j.trip.2020.100150 (2020).

\section{Declarations}

\section{Acknowledgement}

This work was supported by JSPS KAKENHI, Japan (Grant Numbers JP17H00947).

\section{Author contributions statement}

N. Y. conducted the data analysis, interpretation, and manuscript writing. T. H. contributed to the study design and funding acquisition. H. A. conducted the coding. S. N. contributed to the survey design. T. N. contributed to the study design and supervision. All authors reviewed and approved the final version of the manuscript.

\section{Ethics declarations}


Competing interests

The authors declare no competing interests.

\section{Supplementary Information}

The time spent outside used in this study was collected in a retrospective manner and based on the subjective memory of the respondents. iPhone step count data were also obtained through the questionnaire survey. Although the time spent outside and the step count are different indicators, a clear correlation is expected between the two, so we can accept a certain reliability of the self-reported time spent outside if it is related to the step count recorded on the iPhone.

The step count data were collected from screenshots of the respondents' iPhones. Approximately half of the sample used in the multilevel analysis (492 out of 906 samples) had a valid response for the screenshot of the step count data. This low valid response rate is mostly due to the complicated procedure of taking the screenshots for each survey period. Respondents were asked to take three screenshots to cover mid-February to mid-May. The step count data were generated by a program that read the screenshots and automatically recognized the step count for each day. Since step count data are obtained on a daily basis, the counts averaged to correspond to the period of time spent outside. The analysis was conducted with data obtained after late February because sufficient data were not collected for mid-February.

Structural equation modeling was used to analyze the reliability of the reported time spent outside (Fig. S1). Two multilevel models were fitted simultaneously to the trends in the time spent outside and trends in the step count for each individual. The key point of this model is the relationship between the trend (slope) for time spent outside and the trend (slope) for the step count. In this model, the error terms for each time period have covariance with the error term in the adjacent periods. However, the error terms are not depicted in the figure because they are too complicated. The software used for the analysis was Amos version 19.

The results show that the reported time spent outside is fairly reliable. The model is significant according to a chi squared test ( $p$ value $<0.001$ ). The indicators of model fitness are CFI=0.878 and RMSEA=0.148. The standardized path coefficient between the slope for time spent outside and step count is 0.335 ( $p$ value $<0.001$ ). The multiple correlation coefficient for the slope for time spent outside is 0.128 . Although the relation is not strong, there is a significant relation between the trend in time spent outside and step count.

\section{Tables}

Table 1. Descriptive statistics of the variables 


\begin{tabular}{|c|c|c|c|c|c|}
\hline & & \multicolumn{2}{|c|}{$\begin{array}{l}\text { Sample used in } \\
\text { multilevel } \\
\text { analysis }\end{array}$} & \multicolumn{2}{|c|}{$\begin{array}{l}\text { Sample used in } \\
\text { correspondence } \\
\text { analysis }\end{array}$} \\
\hline & & Number & $\%$ & Number & $\%$ \\
\hline \multirow[t]{8}{*}{ Personal attributes } & Age $20 \mathrm{~s}$ & 172 & 19.0 & 186 & 20.0 \\
\hline & Age $30 \mathrm{~s}$ & 231 & 25.5 & 235 & 25.3 \\
\hline & Age 40s & 273 & 30.1 & 276 & 29.7 \\
\hline & Age 50s & 230 & 25.4 & 231 & 24.9 \\
\hline & Gender male & 458 & 50.6 & 468 & 50.4 \\
\hline & Gender female & 448 & 49.4 & 460 & 49.6 \\
\hline & Residence metropolitan area & 494 & 54.5 & 503 & 54.2 \\
\hline & $\begin{array}{l}\text { Residence nonmetropolitan } \\
\text { area }\end{array}$ & 412 & 45.5 & 425 & 45.8 \\
\hline \multirow[t]{7}{*}{ Internet use } & Daily shopping & 299 & 33.0 & 307 & 33.1 \\
\hline & Non-daily shopping & 87 & 9.6 & 88 & 9.5 \\
\hline & Mail/Messages & 311 & 34.3 & 318 & 34.3 \\
\hline & Socializing & 104 & 11.5 & 105 & 11.3 \\
\hline & Exercise & 178 & 19.6 & 180 & 19.4 \\
\hline & Leisure/Entertainment & 420 & 46.4 & 429 & 46.2 \\
\hline & Work/Study & 185 & 20.4 & 188 & 20.3 \\
\hline \multirow[t]{5}{*}{ Internet access } & $\begin{array}{l}\text { Don't have a broadband } \\
\text { connection }\end{array}$ & 59 & 6.5 & 60 & 6.5 \\
\hline & Have traffic volume limit & 79 & 8.7 & 79 & 8.5 \\
\hline & Don't know how to shop online & 12 & 1.3 & 12 & 1.3 \\
\hline & $\begin{array}{l}\text { Workplace doesn't support } \\
\text { telework }\end{array}$ & 133 & 14.7 & 134 & 14.4 \\
\hline & $\begin{array}{l}\text { Don't have a personal } \\
\text { computer }\end{array}$ & 65 & 7.2 & 65 & 7.0 \\
\hline Commercial district & $\begin{array}{l}\text { Living within commercial } \\
\text { district }\end{array}$ & 68 & 7.5 & 68 & 7.3 \\
\hline \multirow{2}{*}{$\begin{array}{l}\text { Less visited } \\
\text { destinations }\end{array}$} & Supermarket & 247 & 27.3 & 251 & 27.0 \\
\hline & Convenience store & 175 & 19.3 & 177 & 19.1 \\
\hline
\end{tabular}




\begin{tabular}{|llllll|}
\hline & Park & 219 & 24.2 & 224 & 24.1 \\
\hline & Shopping mall & 657 & 72.5 & 673 & 72.5 \\
\hline Restaurant & 660 & 72.8 & 676 & 72.8 \\
\hline Workplace/School & 237 & 26.2 & 240 & 25.9 \\
\hline Time spent outside & & Mean & SD & Mean & SD \\
\hline & Mid-February & 8.6 & 2.4 & 8.9 & 5.0 \\
\hline & Late February & 8.2 & 2.5 & 8.4 & 5.0 \\
\hline & Early March & 7.1 & 2.8 & 7.4 & 5.3 \\
\hline & Mid-March & 6.4 & 2.9 & 6.7 & 5.3 \\
\hline & Late March & 5.7 & 2.9 & 6.0 & 4.6 \\
\hline & Early April & 4.5 & 2.8 & 4.7 & 3.9 \\
\hline & Mid-April & 3.9 & 2.8 & 4.0 & 3.7 \\
\hline & Late April & 3.5 & 2.7 & 3.7 & 3.7 \\
\hline Early May & 3.3 & 2.6 & 3.5 & 3.5 \\
\hline Mumber of samples & Mid-May & 3.9 & 2.8 & 4.0 & 4.1 \\
\hline
\end{tabular}

Table 2. Results of the multilevel linear regression analysis 


\begin{tabular}{|c|c|c|c|c|c|}
\hline & Fixed effects & Model 1 & $\mathrm{p}$-value & Model 2 & $\mathrm{p}$-value \\
\hline \multirow[t]{3}{*}{$\beta_{0 j}$} & $Y_{00}$ & 5.509 & $p<0.0001$ & 8.592 & $p<0.0001$ \\
\hline & School closure & & & -1.153 & $p<0.0001$ \\
\hline & $\begin{array}{l}\text { The Declaration of a State of } \\
\text { Emergency }\end{array}$ & & & -1.121 & $p<0.0001$ \\
\hline \multirow[t]{9}{*}{$\beta_{1 j}$} & $Y_{10}$ & & & -0.334 & $p<0.0001$ \\
\hline & Internet use & & & & \\
\hline & Daily shopping & & & -0.049 & 0.0149 \\
\hline & Socializing & & & -0.151 & $p<0.0001$ \\
\hline & Exercise & & & -0.091 & 0.0007 \\
\hline & Leisure/Entertainment & & & -0.095 & $p<0.0001$ \\
\hline & Workplace doesn't support telework & & & 0.109 & 0.0002 \\
\hline & Male (Ref. Female) & & & 0.060 & 0.0041 \\
\hline & Commercial district & & & 0.101 & 0.0105 \\
\hline \multirow[t]{5}{*}{ Variance } & $r_{i j}$ & 6.871 & & 1.757 & \\
\hline & $\mathrm{u}_{0 \mathrm{j}}$ & 4.012 & & 6.373 & \\
\hline & $u_{1 j}$ & & & 0.132 & \\
\hline & AIC & 44920.88 & & 35542.90 & \\
\hline & Number of Sample & 906 & & 906 & \\
\hline
\end{tabular}

\section{Figures}




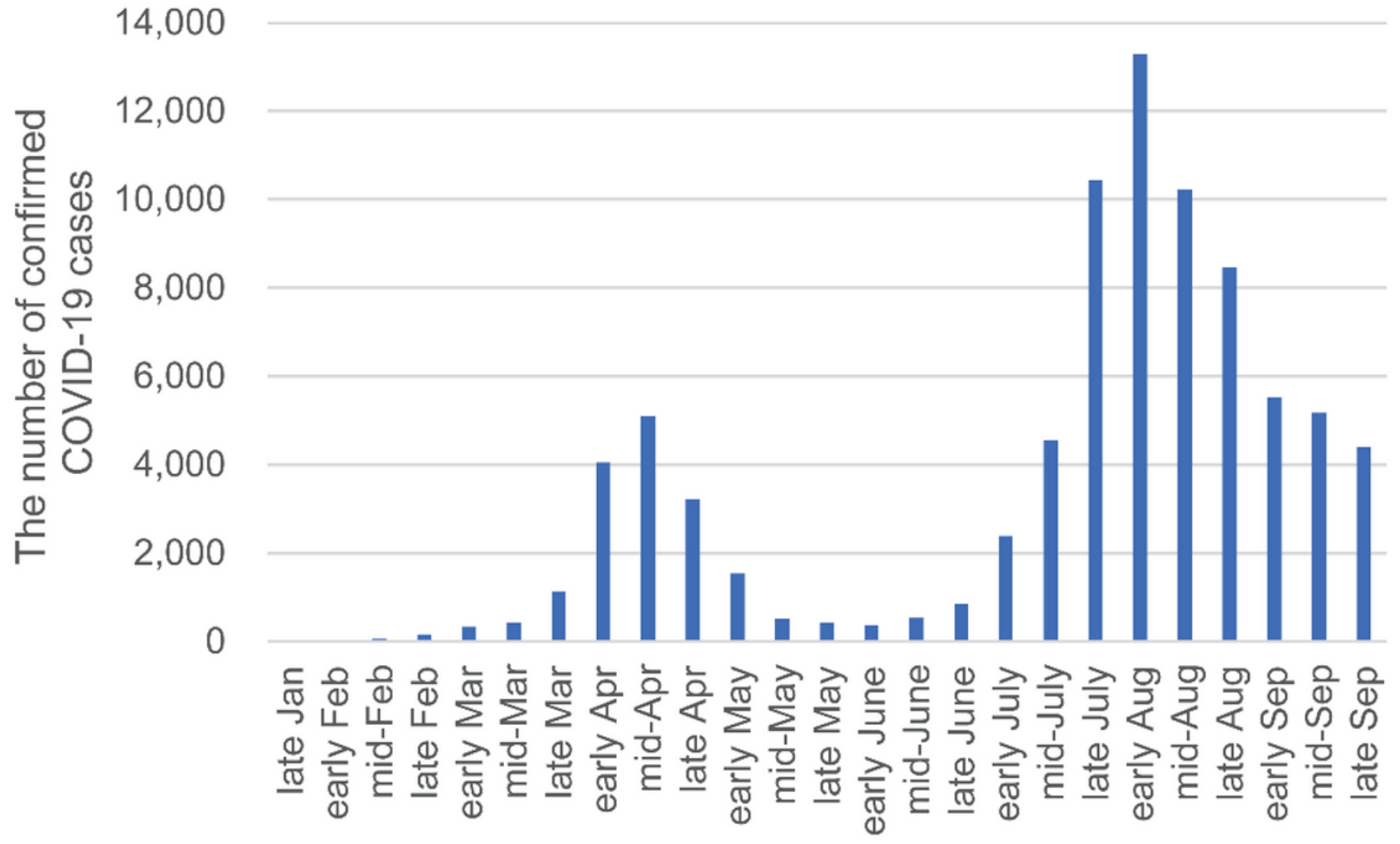

Figure 1

The number of confirmed COVID-19 cases in Japan Source: Ministry of Health, Labor and Welfare (https://www.mhlw.go.jp/stf/covid-19/open-data.html) 


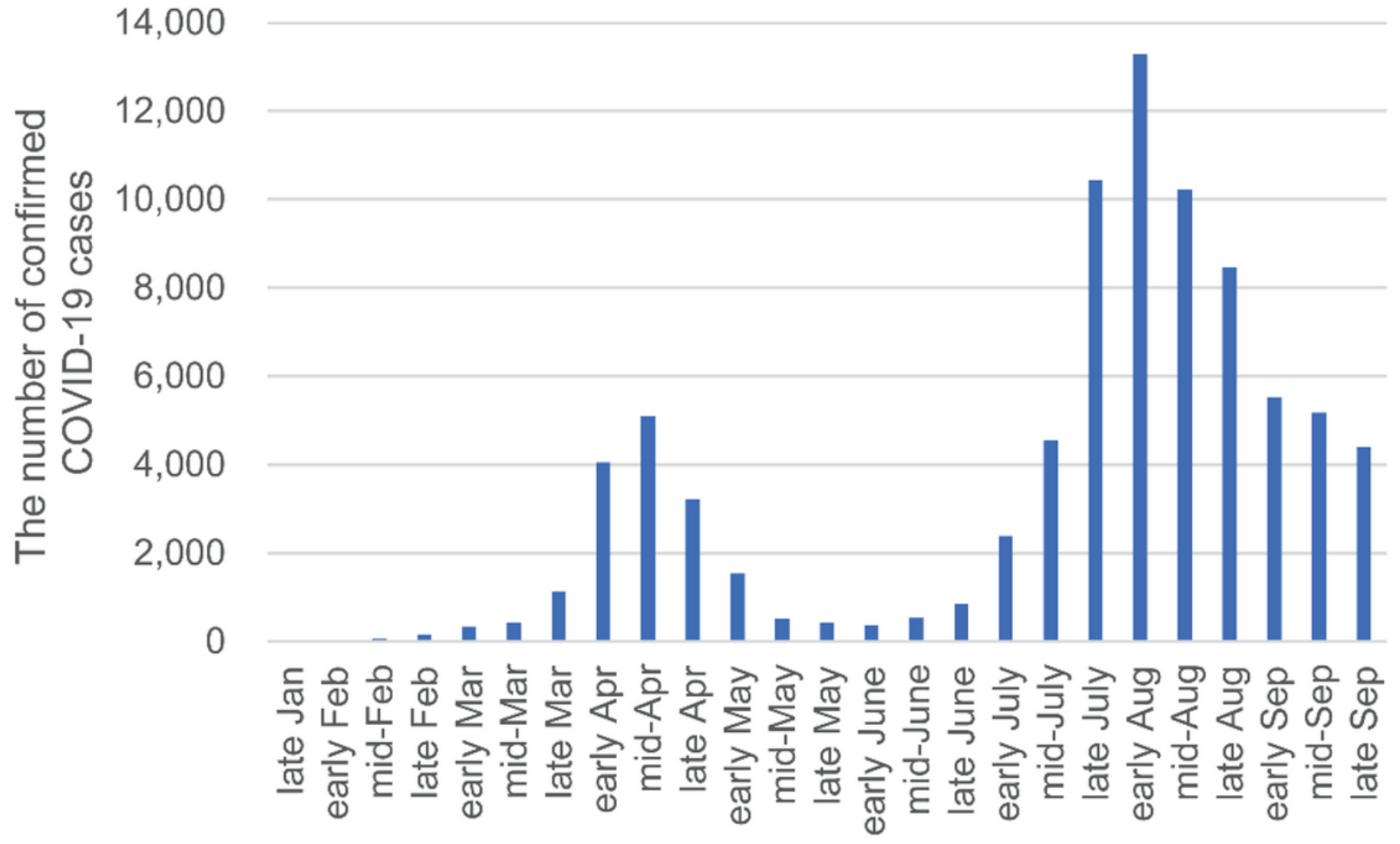

Figure 1

The number of confirmed COVID-19 cases in Japan Source: Ministry of Health, Labor and Welfare (https://www.mhlw.go.jp/stf/covid-19/open-data.html) 


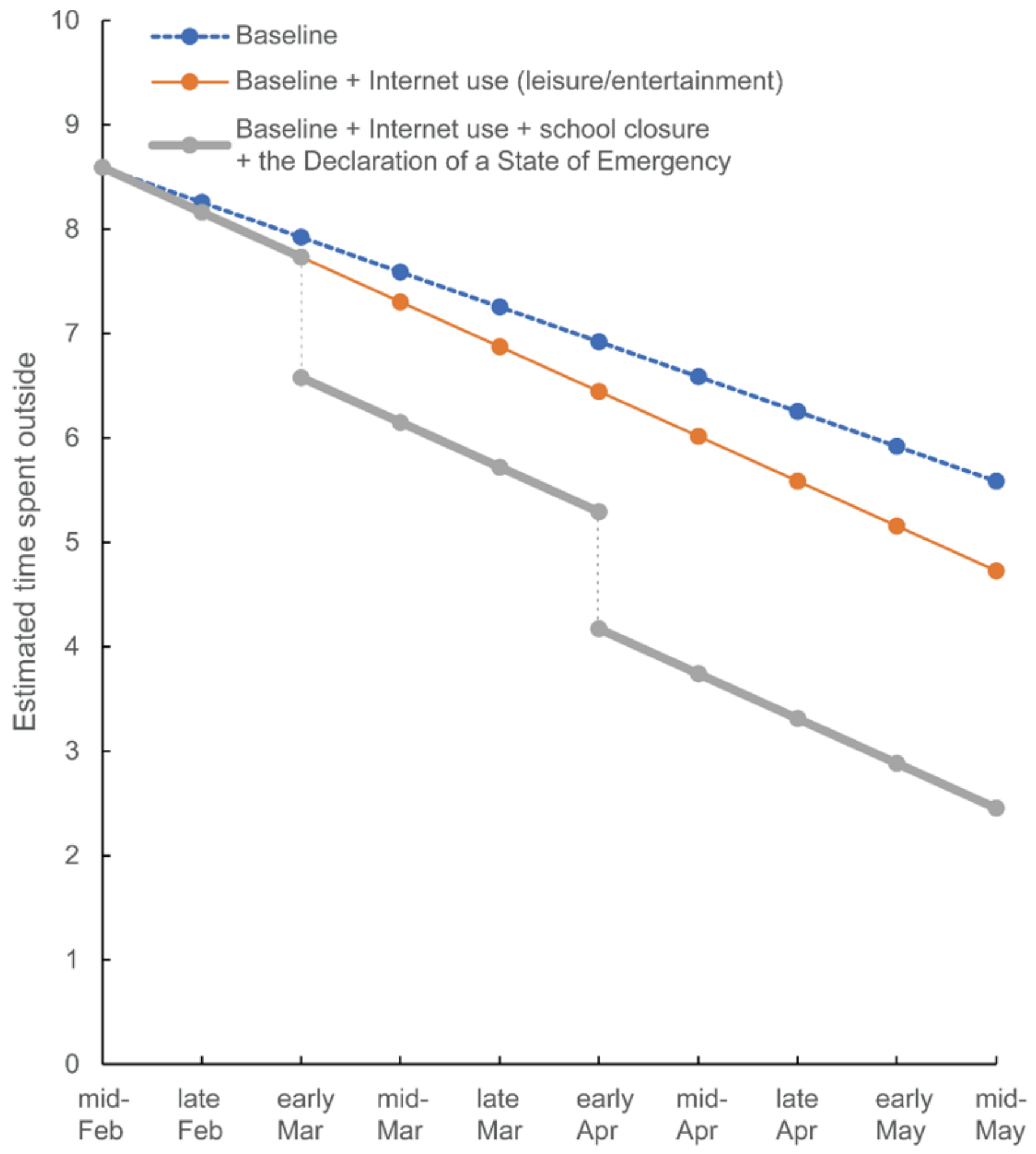

Figure 2

Estimated time spent outside based on the multilevel analysis 


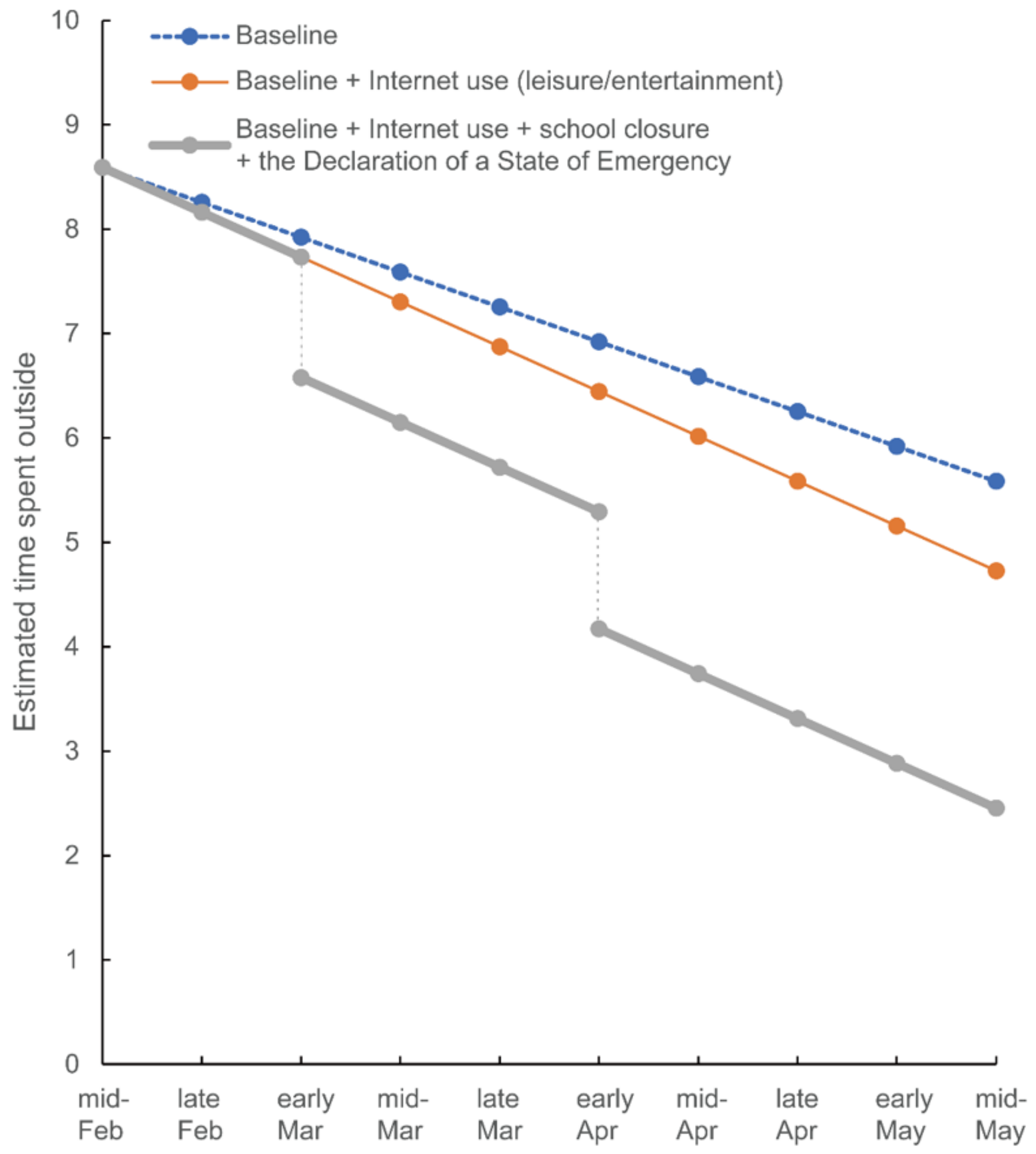

Figure 2

Estimated time spent outside based on the multilevel analysis 


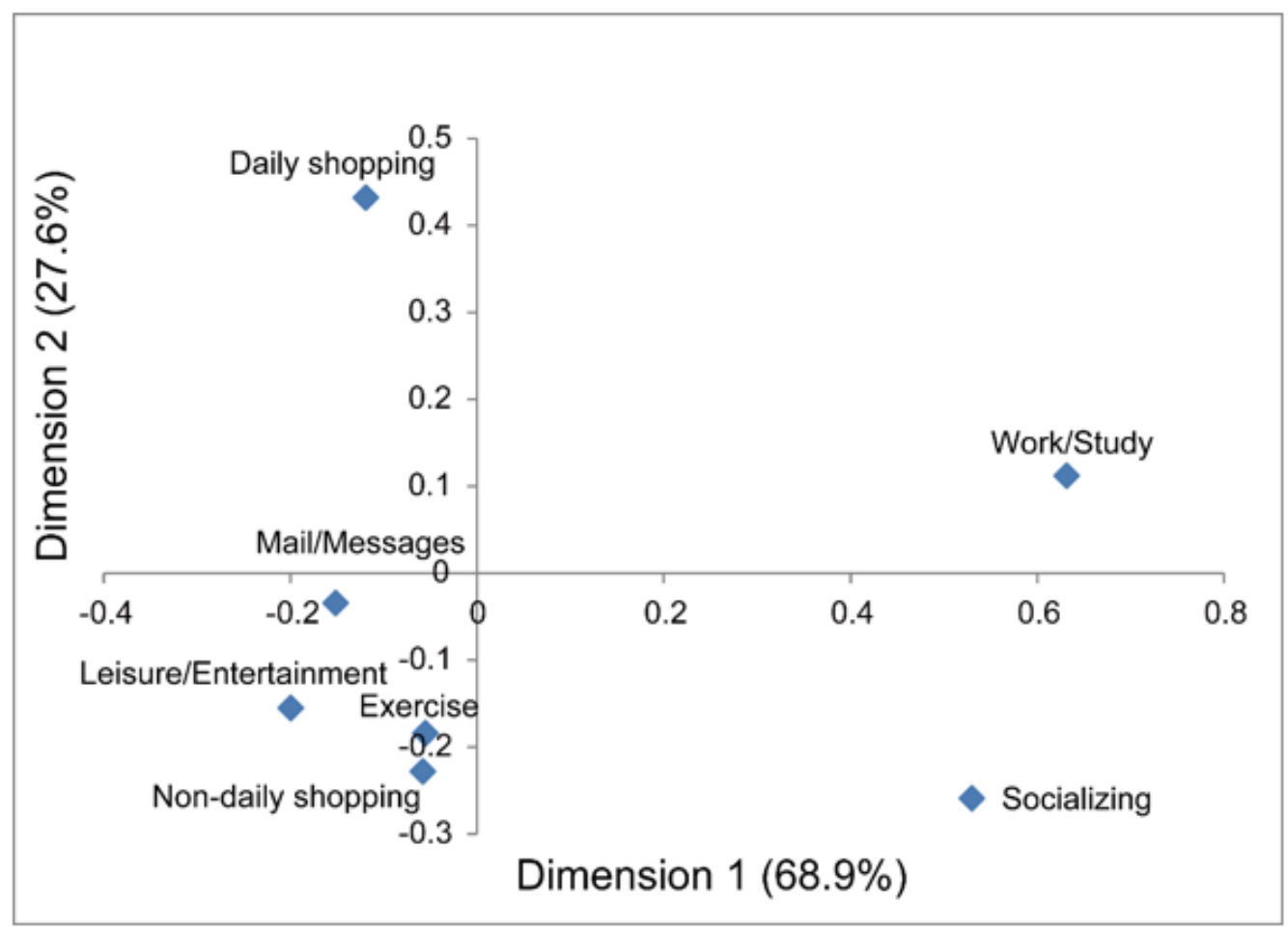

a Plots of the correspondence scores for Internet use

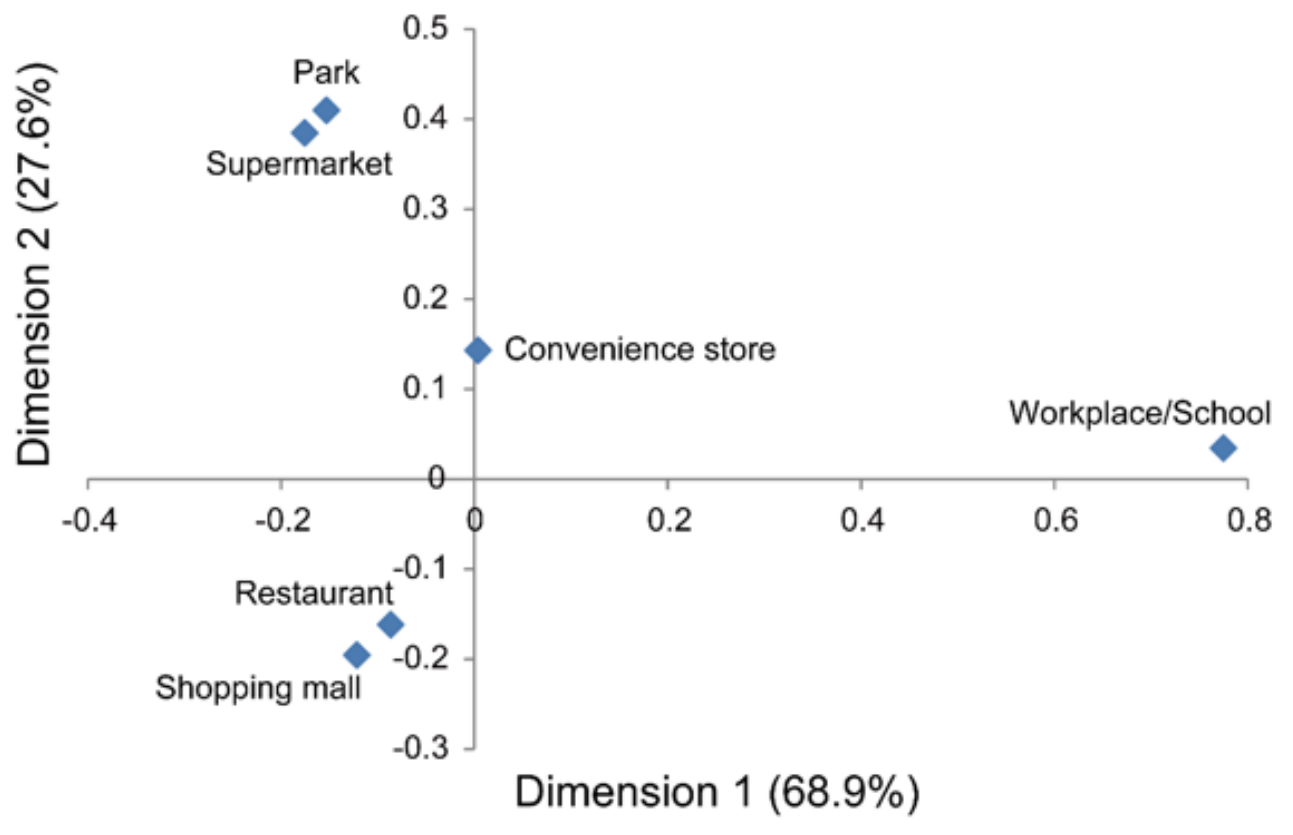

b Plots of the correspondence scores for destinations that respondents refrained from visiting

\section{Figure 3}

Results of the correspondence analysis 


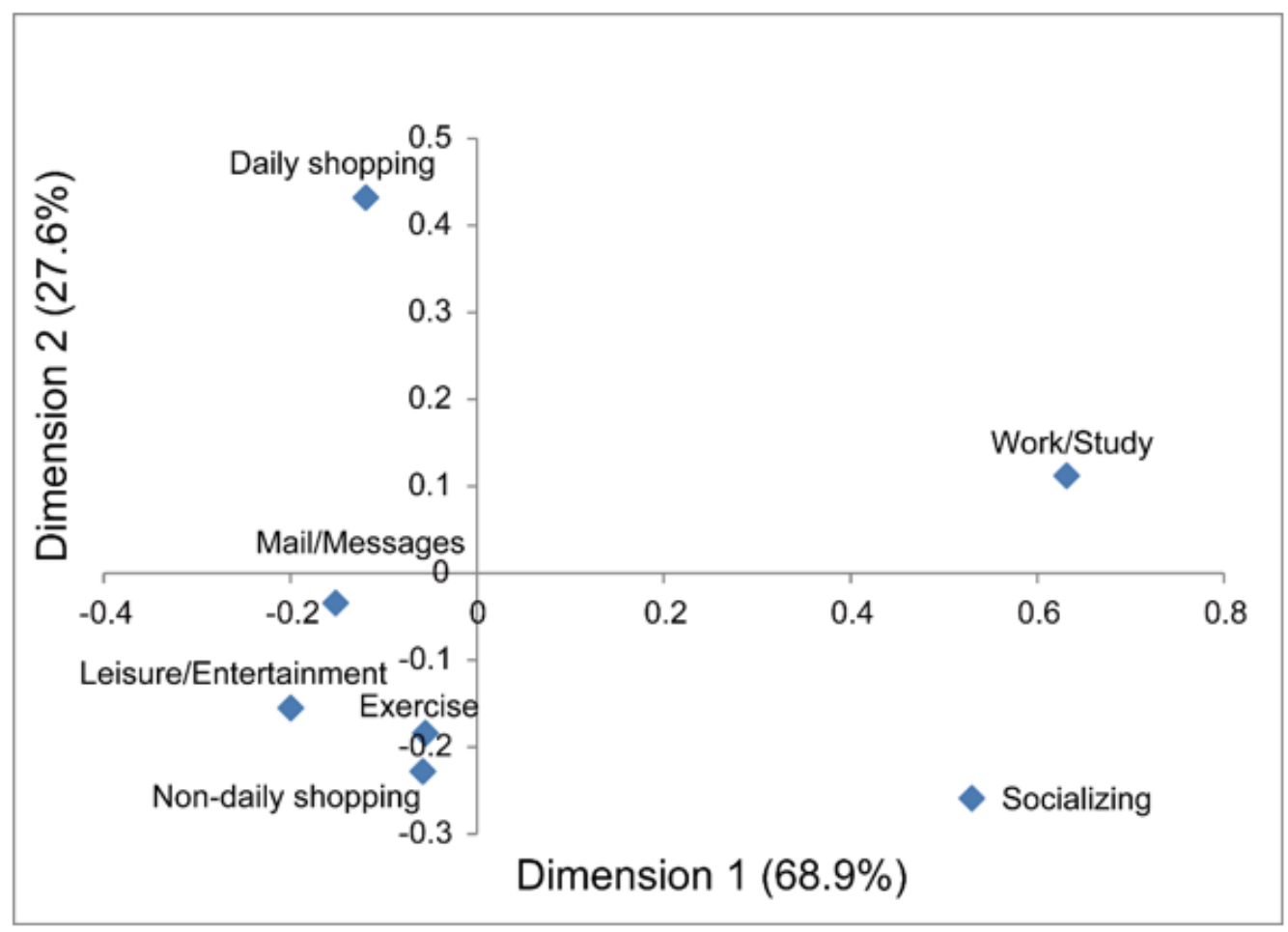

a Plots of the correspondence scores for Internet use

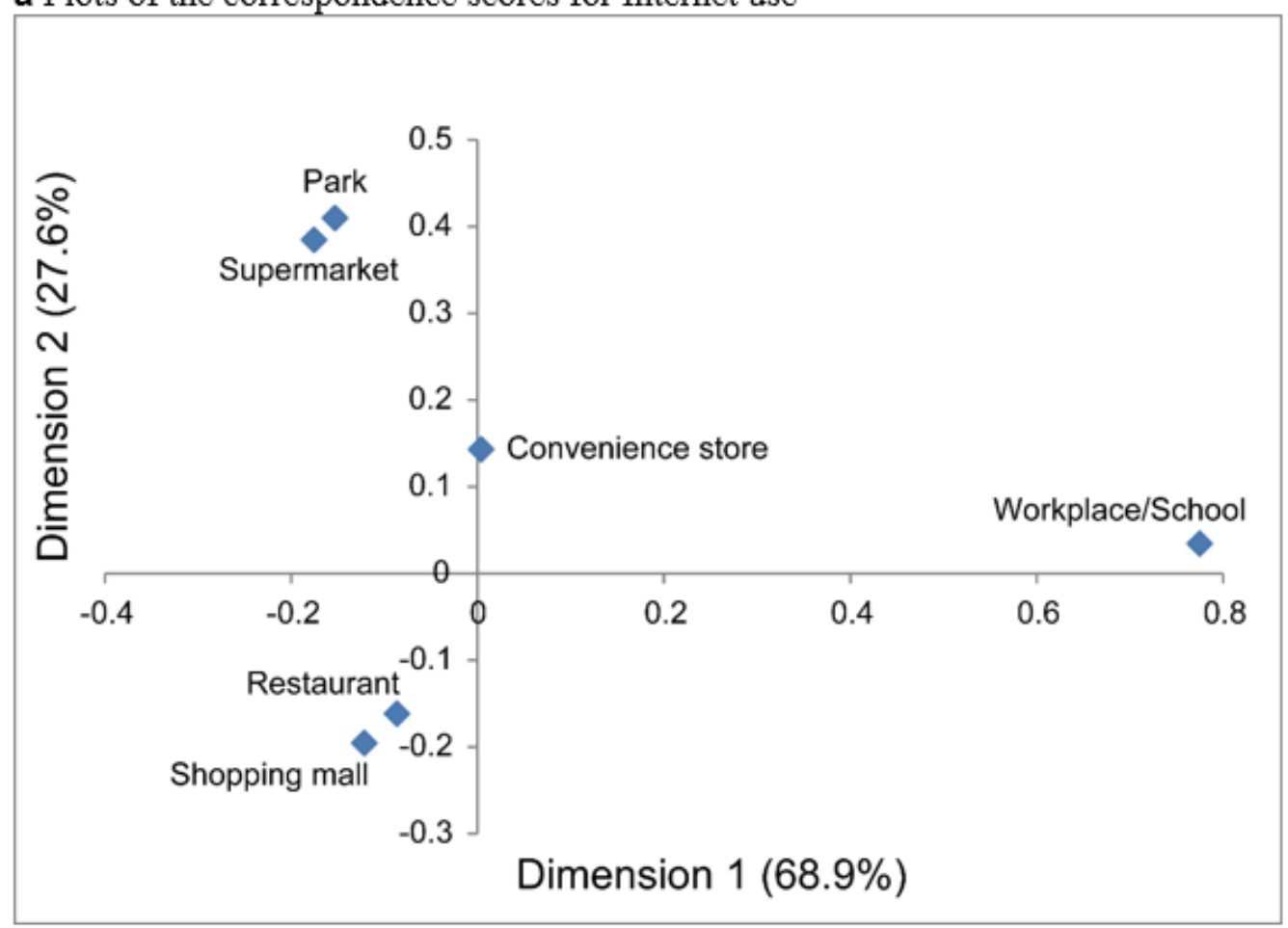

b Plots of the correspondence scores for destinations that respondents refrained from visiting

\section{Figure 3}

Results of the correspondence analysis

\section{Supplementary Files}

This is a list of supplementary files associated with this preprint. Click to download. 
- FigureS1.png

- Figures1.png

Page 23/23 